\title{
¿Qué fue la enmienda de 1972?
}

\author{
What was the 1972 amendment?
}

Qual foi a emenda de 1972?

Quel était l'amendement de 1972?

1972年的修正案是什么?

\section{Diego Gabriel Presa ${ }^{1}$ \\ Universidad Nacional de La Plata - Argentina}

Revista Derechos en Acción ISSN 2525-1678/ e-ISSN 2525-1686

Año 5/N 17 Primavera 2020 (21 septiembre a 20 diciembre), 419-434

DOl: https://doi.org/10.24215/25251678e465

Recibido: 01/09/2020

Aprobado: 15/09/2020

Resumen: El presente trabajo explica que fue la enmienda constitucional de 1972, instaurada por un régimen cívico militar, que modificaría el texto constitucional de 1853 con sus reformas de 1860, 1866, 1898 y 1957, en una sociedad que no encontraba su rumbo político, como consecuencia de las diferentes intervenciones cívico militares, el análisis de la misma intenta mostrar sus características. Concluye el autor afirmando que la enmienda de 1972, fue una mala experiencia, pensada desde un "laboratorio" donde se suponía que saldría la mejor versión de una constitución, el tiempo demostraría que estaba alejada del sustento y la legitimidad que solo el pueblo votando puede otorgar.

Palabras clave: enmienda constitucional, 1972, reforma, Constitución Nacional

Abogado, egresado de la Facultad de Ciencias Jurídicas y Sociales de la UNLP, Relator de la Comisión de Asuntos Constitucionales y Justicia de la Honorable Cámara de Diputados de la Provincia de Buenos Aires (ORCID: https://orcid.org/0000-0003-3315-9301). 
Abstract: This work explains that it was the constitutional amendment of 1972, established by a civil military regime, which would modify the constitutional text of 1853 with its reforms of 1860, 1866, 1898 and 1957 , in a society that could not find its political direction, as a consequence of the different civic-military interventions, its analysis attempts to show their characteristics. The author concludes stating that the 1972 amendment was a bad experience, thought from a "laboratory" where the best version of a constitution was supposed to come out, time would show that it was far from the sustenance and legitimacy that only the people voting can grant.

Keywords: constitutional amendment, 1972, reform, National Constitution

Resumo: Este trabalho explica que foi a emenda constitucional de 1972, instituída por um regime civil militar, que modificaria o texto constitucional de 1853 com suas reformas de 1860, 1866, 1898 e 1957, numa sociedade que não conseguia encontrar seu rumo político, em decorrência das diferentes intervenções cívico-militares, a sua análise procura mostrar as suas características. 0 autor conclui afirmando que a emenda de 1972 foi uma péssima experiência, pensada a partir de um "laboratório" onde deveria sair a melhor versão de uma constituição, o tempo mostraria que estava longe do sustento e da legitimidade que só o votante pode conceder.

Palavras-chave: emenda constitucional, 1972, reforma, Constituição Nacional

Résumé: Cet ouvrage explique que c'est l'amendement constitutionnel de 1972, mis en place par un régime civilo-militaire, qui modifiera le texte constitutionnel de 1853 avec ses réformes de 1860, 1866, 1898 et 1957, dans une société qui ne pouvait trouver sa direction politique, en conséquence des différentes interventions civico-militaires, son analyse tente de montrer leurs caractéristiques. L'auteur conclut en déclarant que l'amendement de 1972 a été une mauvaise expérience, pensée d'un «laboratoire» où la meilleure version d'une constitution était censée sortir, le temps montrerait que c'était loin de la subsistance et de la légitimité que seuls les votants peuvent subvention.

Mot-clés: amendement constitutionnel, 1972, réforme, Constitution nationale 
摘要：这项工作解释说这是由民用军事政权制定的1972年宪法修正 案它将在一个无法找到其政治方向的社会中修改1853年的宪法文本 并进行1860，18661898和1957年的改革对于不同的军民干预措施 其分析试图显示其特征作者的结论是说1972年的修正案是一个糟糕 的经历是从一个“实验室”想到的宪法的最佳版本本应出炉时间证明 只有投票的人才能维持和合法性授予

关键字: 宪法修正案, 1972年, 改革, 国家宪法

\section{Presentación}

El presente explica que fue la enmienda constitucional de 1972, instaurada por un régimen cívico militar, que modificaría el texto constitucional de 1853 con sus reformas de 1860, 1866, 1898 y 1957, en una sociedad que no encontraba su rumbo político, como consecuencia de las diferentes intervenciones cívico militares, el análisis de la misma intenta mostrar sus características.

\section{La enmienda de 1972}

La Republica Argentina tendría por ley $19608^{2}$ una enmienda en su texto constitucional. Era el año 1972, la Junta Militar de la lánguida Revolución Argentina, daba sus pasos finales, el gobierno cívico militar era encabezado por Alejandro Agustín Lanusse $^{3}$, el general que detentaba el poder real y formal desde hacía un tiempo.

Su gobierno cívico militar, había decido modificar el texto constitucional, la experiencia de 1949, donde la constitución había sino anulada por un bando militar, cuestionada por el quórum para la sanción de la ley de necesidad de reforma $13233^{4}$,

\footnotetext{
2 Publicada en el Boletín Oficial el 11 de mayo de 1972.

3 1918-1996, militar y dictador argentino, presidente de facto entre 1971 a 1973.

4 Publicada en el Boletín Oficial el 8 de septiembre de 1948, primer gobierno de Juan Domingo Perón 1946 a 1952.
} 
al interpretarse que el mismo era de los presentes y no de los miembros totales de la Cámara, quórum que ya se había utilizado con el mecanismo de los miembros presentes en las reforma de 1860 y 1866, es decir cuyas leyes de declaración de necesidad de reforma, habían sido declaradas por los dos tercios aplicados sobre los miembros presentes de la Cámara, este hecho inaudito motivo la anulación de la constitución de 1949.

La reforma de 1957, impulsada por otro gobierno cívico militar ${ }^{5}$, trajo otra mala experiencia, al convocarse por el decreto $3838 / 1957^{6}$ del Poder Ejecutivo Nacional de facto y no haber Congreso, que discutiera y sancionara la ley que declarara la necesidad de reforma, por lo cual no se había tenido en cuenta los dos tercios de absolutamente de nada. Los legalistas que cuestionaban la reforma de 1949, habían borrado toda legalidad, con la anulación de esa constitución por bando militar y la convocatoria por decreto. La convención constituyente de 1957, termino sin consenso y con la introducción del artículo 14 bis y un agregado al artículo 67 inciso 11, diluyéndose en debates estériles.

En ese año de 1972, el gobierno cívico militar, pretendía legalizar el peronismo y permitir su participación en elecciones, introduciendo modificaciones en la Constitución que podrían llevarlo a una derrota electoral por vez primera, se habían propuesto una enmienda que llevaría a un nuevo tiempo, los fundamentos del decreto ley que declara la necesidad, también al margen del artículo $30^{\circ}$ de la Constitución Nacional, por no existir el Congreso Nacional, expresaba en sus considerandos “...Que el Gobierno Nacional, en diversas oportunidades, ha reafirmado que para la consolidación de los fines revolucionarios, habían de llevarse a cabo ciertas reformas a la Constitución Nacional...", era destinada supuestamente a cumplir los "fines revolucionarios" de un gobierno al margen de la ley y la Constitución.

\footnotetext{
5 Gobierno cívico militar de 1955 a 1958.

6 Confeccionado con fecha 12 de abril de 1957.
} 
El decreto ley declaraba como necesidad de reforma los artículos $1^{\circ}, 5^{\circ}, 42^{\circ}, 45^{\circ}, 46^{\circ}, 48^{\circ}, 55^{\circ}, 56^{\circ}, 67^{\circ}$ inc. $7^{\circ}, 68^{\circ}, 69^{\circ}$, $72^{\circ}, 77^{\circ}, 81^{\circ}, 87^{\circ}$ y $96^{\circ}$.

Los artículos habían sido analizados por la Comisión Asesora del Plan Político, que había designado el Ministro del Interior, Arturo Mor Roig ${ }^{7}$, la cual estaba integrada por los Doctores Germán J. Bidart Campos ${ }^{8}$, Carlos María Bidegain', Natalio R. Botana $^{10}$, Carlos S. Fayt ${ }^{11}$, Mario Justo López ${ }^{12}$, Julio C. Oyhanarte $^{13}$, Pablo A. Ramella ${ }^{14}$, Adolfo Rouzat ${ }^{15}$, Alberto A. Spota ${ }^{16}$, entre otros.

Esa Comisión remitió al Poder Ejecutivo un informe sobre las reformas constitucionales propuestas, con dictámenes independientes, por mayoría y minoría, las cuales determinaron la ley 19608 citada.

Así el Poder Ejecutivo y la Junta Militar que lo acompañaban, dictaron el denominado "Estatuto Fundamental" que disponía modificaciones al texto constitucional de 1853 con las reformas de 1860, 1866, 1898 y 1957 las cuales se tomaron de las propuestas por la Comisión Asesora aunque no en su totalidad, en

\footnotetext{
7 1914-1974, político argentino, diputado nacional por la Unión Cívica Radical y Ministro del Interior del gobierno cívico militar, seria asesinado por Montoneros.

8 1927-2004, abogado, profesor y jurista argentino.

9 1916-2016, abogado y jurista argentino.

10 1937, abogado y jurista argentino.

11 1918-2016, abogado, escritor, docente, y juez argentino, ministro de la Corte Suprema de Justicia de la Nación Argentina entre 1983 a 2015, de origen socialista.

12 1915-1989, abogado argentino y Procurador General de la Nación entre 1980 a 1983 en el gobierno cívico militar de 1976 a 1983.

13 1920-1997, abogado argentino, egresado de la Facultad de Derecho y Ciencias Sociales de la UNLP, ministro de la Corte Suprema de Justicia de la Nación entre 1958 a 1962, y 1989 a 1991, de origen radical.

14 1906-1993, abogado constitucionalista, ministro de la Corte Suprema de Justicia de la Nación entre 1975 a 1976, de origen peronista.

15 1906-1995, abogado argentino, de origen radical.

16 1920-1991, abogado y docente universitario, identificado con el radicalismo.
} 
sus considerandos decían que la “...Junta de Comandantes en Jefe, en ejercicio del poder revolucionario en nombre y representación de las Fuerzas Armadas, se ha propuesto restituir la soberanía al pueblo y asegurar una democracia representativa, auténtica y estable...", recordemos que la inestabilidad se da por la participación militar en la política hecho que no tendría que haber ocurrido nunca.

Dejaban en claro que "...las disposiciones temporarias que se establecen no afectan los derechos, declaraciones y garantías que consagra la primera parte de la Constitución Nacional..." derechos y garantías, que se encontraban en constante vulneración por el mismo gobierno cívico militar.

Entre los considerandos manifestaban "...Que sobre estas normas será el pueblo quien, en ejercicio de su soberanía, decida acerca de su incorporación definitiva a la Constitución Nacional...”. En el artículo $1^{\circ}$ de dicho Estatuto se modificaban los artículos $42^{\circ}, 45^{\circ}, 46^{\circ}, 48^{\circ}, 55^{\circ}, 56^{\circ}, 67^{\circ}$ inciso $7^{\circ}, 77^{\circ}, 81^{\circ}$, $86^{\circ}$ incisos $11^{\circ}$ y $12^{\circ}, 87^{\circ}$ y $96^{\circ}$, dándoles su nueva redacción, la cual analizaremos.

El artículo $42^{\circ}$ del estatuto establecía “...Los diputados duran en su representación cuatro años y son reelegibles indefinidamente. Se elegirán en la oportunidad prevista en el Artículo $81 \ldots "$

El artículo $42^{\circ}$ del texto Constitucional expresaba “...Los diputados durarán en su representación por cuatro años, y son reelegibles; pero la Sala se renovará por mitad cada bienio; a cuyo efecto los nombrados para la primera Legislatura, luego que se reúnan, sortearán los que deban salir en el primer período...".

La reforma mantenía los diputados con mandato de cuatro años, pero eliminaba la renovación de las Cámaras cada bienio, el artículo 81 preveía la realización de elecciones al menos seis meses antes de terminar los mandatos. Al restringirse las renovaciones cada bienio se pensaba que se le daba estabilidad política al gobierno que fuera electo, lo que no se pensó es si ese gobierno podría gobernar en su caso con una Cámara en 
minoría, debido que no tendría posibilidad de alterar democráticamente la composición de la Cámara con las elecciones de medio término.

En lo que respecta al artículo $45^{\circ}$ se introdujo el siguiente texto "...Sólo ella ejerce el derecho de acusar ante el Senado al presidente, vicepresidente, sus ministros y a los miembros de la Corte Suprema en las causas de responsabilidad que se intenten contra ellos, por mal desempeño o por delito en el ejercicio de sus funciones; o por crímenes comunes, después de haber conocido de ellos y declarado haber lugar a la formación de causa por mayoría de dos terceras partes de sus miembros presentes..." Aquí se quitaba de los acusados por la Cámara de Diputados, a los Tribunales Inferiores de la Nación.

Los Tribunales inferiores, pasarían a ser juzgado en juicio público mediante acusación ante un jurado, que estaría integrado por igual número de miembros del Poder Judicial, del Poder Legislativo y abogados; todos ellos elegidos antes del 19 de enero de cada año, dejando a una ley del futuro Congreso su organización y el procedimiento aplicable, esto quedaba plasmado en el artículo $96^{\circ}$.

En el artículo $46^{\circ}$, se modificaba la composición del Senado Nacional, el cual se integraría con tres senadores, elevando su número a 69 -recordemos que Tierra del Fuego no era Provincia aún-, dado que la Constitución establecía dos senadores por Provincia, ahora serian tres, correspondiendo dos a la mayoría y uno a la minoría, siendo electos también en la oportunidad establecida en el artículo $81^{\circ}$ de la enmienda. En la reforma de 1994 se establecería nuevamente esta composición del Senado.

En al artículo $48^{\circ}$ del Estatuto se modificaba el mandato pasando a ser de cuatro años con posibilidad de reelección, sin renovaciones por bienio, en la Constitución, el mandato había sido determinado en nueve años renovable la Cámara Alta por tercios cada tres años. El gobierno cívico militar intentaba evitar las elecciones de medio término, limitando la democracia en si misma. 
El Capítulo III de la Constitución, en lo que respecta a "Disposición Comunes a Ambas Cámaras", se modificaría en el artículo $55^{\circ}$ “...Ambas Cámaras se reunirán por propia convocatoria en sesiones ordinarias todos los años desde el 19 de abril hasta el 30 de noviembre. Pueden disponer su prórroga por un plazo no mayor de treinta días corridos. También pueden ser convocadas extraordinariamente por el presidente de la $\mathrm{Na}$ ción o a solicitud de la cuarta parte de los miembros de cada Cámara. En esta última alternativa el presidente de cualesquiera de ellas deberá citarlos, correspondiendo a los cuerpos decidir si su realización está justificada...", modificaba el periodo de sesiones desde el 19 de abril al 30 de noviembre de cada año, ampliando el mismo, en la Constitución estaba fijado entre el $1^{\circ}$ de mayo al 30 de septiembre de cada año.

Se establecía la posibilidad de convocatoria extraordinaria por el Poder Ejecutivo o a solicitud de una cuarte parte de sus miembros, decidiendo el cuerpo si su convocatoria era justificada, tengamos presente que la convocatoria a la Cámara por sus miembros se hacía con menos del quórum exigido para funcionar.

Se modificó el artículo $56^{\circ}$ estableciendo que “...Cada Cámara es juez de las elecciones, derechos y títulos de sus miembros en cuanto a su validez. El quórum para sesionar se formará con la cuarta parte de sus miembros, pero para la sanción de las leyes y el ejercicio de las atribuciones a que se refiere esta Constitución el quórum será de la mayoría absoluta, salvo en los casos en que se exige una mayoría especial. Un número menor de la cuarta parte podrá compeler a los ausentes a que concurran a las sesiones en los términos y bajo las penas que cada Cámara establecerá...”.

Podemos distinguir en el artículo que se modifica el quórum para darle sentido al artículo $55^{\circ}$, antes se exigía la mayoría absoluta (mitad más uno) y ahora se pasaba a un cuarto de sus miembros, esto al efecto de convocatoria, para la sanción de leyes se mantenía mitad más uno. 
En cuanto a las atribuciones del Congreso, reguladas en el Capítulo IV de la Constitución, en su artículo $67^{\circ}$ inciso $7^{\circ}$ se autorizaba a "...Fijar anualmente el presupuesto de gastos de administración de la Nación y aprobar o desechar la cuenta de inversión. A iniciativa del Poder Ejecutivo el presupuesto podrá comprender ejercicios de más de un año de duración, pero en ningún caso excederá el período del mandato del presidente de la Nación en ejercicio...".

Aquí se quitaba la atribución del Congreso de realizar el presupuesto, quedando la iniciativa a cargo del Poder Ejecutivo, pudiendo establecer presupuestos superiores al año de duración, sin poder exceder el periodo presidencial.

La Sección II, correspondiente al Poder Ejecutivo, en su Capítulo Primero, que regulaba en cuanto a su naturaleza y duración, se modificaba el artículo $77^{\circ}$, que establecía el mandato del Presidente y Vicepresidente, quedando redactado de la siguiente manera "...El presidente y vicepresidente duran en sus cargos cuatro años y pueden ser reelegidos una sola vez...”, se reducía el periodo presidencial de seis años a cuatro años y se autorizaba la reelección por una vez, el motivo de esta reducción se basaba en que seis años de mandato eran casi de imposible cumplimiento, pero no se hablaba que la mayoría de los presidentes no había cumplido su mandato por las interrupciones cívico militares.

El nuevo artículo $81^{\circ}$ anulaba el Colegio Electoral, evitando la complejidad de acuerdos que este Colegio significaba para quien no obtenía la mayoría de los electores, debemos tener presente que desde 1955 la democracia se encontraba restringida, no solo en los mandatos presidenciales sino en su participación, siendo negada la misma al sector peronista quien no podía votar por sus candidatos al no poder inscribirlos como tales.

El nuevo texto quedaba de la siguiente manera “...El presidente y vicepresidente serán elegidos simultánea y directamente por el pueblo de la Nación, cuyo territorio, a ese efecto formará un distrito único. La elección deberá efectuarse entre 
seis y dos meses antes que concluya el período del presidente en ejercicio. Se proclamarán electos los candidatos que obtuvieren la mayoría absoluta de los votos válidos emitidos. La ley determinará el procedimiento a seguir si ninguno alcanzare esa mayoría, observándose el principio de elección directa...".

Se establecía la elección directa por sufragio, se requería mayoría absoluta y se dejaba librado a la ley el sistema de ballotage o doble vuelta, cuya exigencia era sobrepasar el 50\% de los votos válidos emitidos, la norma que regulo el sistema fue la ley $19862^{17}$.

En lo que respecta al Capítulo III, atribuciones del Poder Ejecutivo, de la Constitución, se modifican el artículo $86^{\circ}$ inciso $11^{\circ}$, el cual quedaba redactado de la siguiente forma "...concurre anualmente a la apertura de las sesiones del Congreso, reunidas al efecto ambas Cámaras conjuntamente, dando cuenta en esa ocasión al Congreso del estado de la Nación, de las reformas prometidas por la Constitución, y recomendando a su consideración las medidas que juzgue necesarias y convenientes...", se quitaba las palabras "hace anualmente" y se reemplazaban por "concurre anualmente", además se modifica el sitio, la Constitución hablaba del "Senado" y la enmienda dice en el "Congreso.

El inciso $12^{\circ}$ del artículo $86^{\circ}$ quedaba redactado de la siguiente manera "...Convoca al Congreso a sesiones extraordinarias cuando un grave interés de orden o de progreso lo requiera..." recordemos que son las atribuciones del Poder Ejecutivo, la redacción original hablaba de prorrogar las sesiones ordinarias del Congreso, o lo convocaba a sesiones extraordinarias, se reemplazan ambos conceptos por la acción de convocar.

Los ministros del Poder Ejecutivo en su artículo $87^{\circ}$ se ajustaban al siguiente texto "...El despacho de los negocios de la Nación estará a cargo de ministros secretarios que refrendarán y legalizarán los actos del presidente por medio de su firma, sin cuyo requisito carecen de eficacia. La ley fijará el número

17 Publicada en el Boletín Oficial el 5 de octubre de 1972. 
de ministros y deslindará los ramos del respectivo despacho...", quitaba el nombre de los ramos de los ministros, dejándolo a cargo de una ley de ministerios, hecho que ya había sido plasmado en la Constitución de 1949 y que con la incorrecta anulación de 1956 y la ratificación de ella de la convención de 1957 , se había vuelto al texto donde estaban los nombres de los ministros que acompañaban al presidente.

En el artículo $2^{\circ}$, del llamado Estatuto Fundamental, se hacían agregados a distintos artículos, entre ellos 68, 69, 71, 96, y 105 de la Constitución Nacional, incorporando distintos párrafos a los mismo.

Comenzaban por el Capítulo V, de la formación y sanción de las leyes, que tenía la Constitución, en su artículo 68 por el cual las leyes pueden tener principio en cualquiera de las Cámaras del Congreso, donde se hacía una excepción a la ley de presupuesto que era exclusiva de la Cámara de Diputados según el artículo $44^{\circ}$, ahora se agregaba, artículo $68^{\circ}$ “...La iniciativa de las leyes de presupuesto y ministerios corresponde exclusivamente al Poder Ejecutivo. El Congreso podrá disminuir pero no aumentar las autorizaciones de gastos incluidos en el proyecto de presupuesto, y no podrá sancionar proyectos de leyes que ordenen gastos sin crear los recursos necesarios para su atención...", quitándole esa atribución como he visto, pero además podía el Congreso disminuir las partidas presupuestaras pero no aumentarlas, limitando a cualquier gasto nuevo a tener los recursos para su respaldo.

Las reformas continuaban con el artículo $69^{\circ}$ de la Constitución originaria, el cual establecía, el tratamiento de los proyectos de ley, indicando su pase una vez aprobado a la Cámara revisora y de ser aprobado por esta al Poder Ejecutivo, para su examen, quien lo promulgaría en su caso de corresponder.

El nuevo artículo 69, determinaba “...En cualquier período de sesiones el Poder Ejecutivo puede enviar al Congreso proyectos con pedido de urgente tratamiento, que deberán ser considerados dentro de los treinta días corridos de la recepción 
por la Cámara de origen y en igual plazo por la revisora. Estos plazos serán de sesenta días para el proyecto de ley de presupuesto. Cuando éste fuere desechado, para considerar el nuevo proyecto cada Cámara tendrá treinta días. La solicitud de tratamiento de urgencia de un proyecto puede ser hecho aun después de la remisión y en cualquier etapa de su trámite. Se tendrá por aprobado aquel que dentro de los plazos establecidos no sea expresamente desechado. Cada Cámara, con excepción del proyecto de ley de presupuesto, puede dejar sin efecto el procedimiento de urgencia si así lo resuelve una mayoría de dos tercios de sus miembros presentes, en cuyo caso se aplica, a partir de ese momento, el ordinario.

Las Cámaras pueden delegar en sus comisiones internas la discusión y aprobación de determinados proyectos, conforme se establezca por ley. Esos proyectos, si obtienen el voto favorable de la mayoría absoluta de los miembros de la comisión, pasan a la otra Cámara donde se observará el mismo procedimiento para la sanción y, en su caso, al Poder Ejecutivo para la promulgación, salvo que un cuarto de los miembros de alguna de las Cámara requiera la votación del proyecto por el cuerpo...".

Autorizaba al Poder Ejecutivo a enviar proyectos de urgente tratamiento, a ser considerados en un plazo de treinta días corridos desde que fuera receptado por la Cámara que se consideraría originaria y de otros treinta días corridos por la Cámara Revisora. Se ampliaba a sesenta días para el caso del presupuesto nacional.

La solicitud de urgente tratamiento, podría hacerse al momento del envío o durante la discusión del proyecto, pero la Cámara con el voto de dos tercios de sus miembros presentes podría dejar sin efecto el título de urgente tratamiento. No se determina ninguna consecuencia o sanción por el no tratamiento del proyecto en los plazos requeridos en el texto de la enmienda.

La enmienda legisla, en un exceso reglamentarista, sobre las comisiones de trabajo del Congreso, estableciendo el voto 
de mayoría absoluta de sus miembros dentro de las comisiones para su aprobación, esta aclaración corresponde porque los miembros de una comisión pueden ser quince diputados pero las Comisiones funcionan con quórum, es decir que pueden no asistir todos y ser aprobados proyectos con la mayoría absoluta surgida del quórum. Entendemos que las comisiones de trabajo del Congreso, deben ser reguladas en el Reglamento Interno de cada Cámara y no como en este caso en el texto de una enmienda en la Constitución.

Esta segunda parte del artículo $69^{\circ}$, autoriza a que solamente la Comisión apruebe el proyecto y lo remita a la Cámara revisora, lo cual podría generar que una ley la discutan y aprueben unas treinta personas, sumando las comisiones de ambas Cámaras y no en el recinto como corresponde, autoriza sí que un cuarto de los miembros requiera la votación en el recinto, es un procedimiento poco democrático y donde la discusión y debate muchas veces no sería público, lo correcto, lo democrático, el consenso, el debate, los acuerdos duraderos en el tiempo justamente surgen en ese debate que se da en el recinto.

Los plazos también se reducían en el artículo $71^{\circ}$, “...Cada Cámara tiene un plazo de quince días corridos para considerar las modificaciones propuestas por la otra, transcurrido el cual se tendrán por aprobados si no se pronunciare expresamente...", peligrosamente deja ante el silencio la repuesta positiva, cuando la doctrina es unánime que el silencio se entiende como una repuesta negativa, y más en una cuestión tan sensible como es una ley.

El Poder Judicial, establecido en la Sección III, Capítulo Primero, con el título "De su naturaleza y duración", sufría una modificación en el artículo 96, el cual regulaba a los Jueces de la Corte Suprema y de los Tribunales inferiores de la Nación, estableciendo que conservarían sus empleos mientras dure su buena conducta y recibiendo una compensación por su trabajo la cual no podría ser disminuida mientras este en funciones, es decir la intangibilidad de las remuneraciones. 
El nuevo artículo 96, impone una nueva redacción “...Los jueces de los tribunales inferiores de la Nación, por las causas de responsabilidad previstas en el Artículo 45 y con los efectos del Artículo 52, serán juzgados en juicio público por acusación ante un jurado, que será integrado por igual número de miembros del Poder Judicial, del Poder Legislativo y abogados; todos ellos elegidos antes del 19 de enero de cada año. La ley determinará su organización y el procedimiento aplicable...”, es un nuevo sistema de juzgamiento de jueces inferiores a cargo de un jurado integrado por igual miembros del Poder Judicial y Legislativo, sumando a los abogados, elegidos antes del 19 de enero de cada años, la fecha es anterior a la culminación de la feria judicial de verano, dejando librado a una ley su organización y procedimiento.

Surge así este proceso, que podríamos llamar de jury de enjuiciamiento, sacándole la competencia al Congreso, expresamente el Poder Ejecutivo no está representado en este jurado, es así como se asimila a un Jury de Enjuiciamiento y no al actual Concejo de la Magistratura que posee un representante del Poder Ejecutivo.

El artículo $105^{\circ}$, modifica el Titulo II, Gobierno de Provincias, donde se establecía que las Provincias se dan sus propias instituciones, elegían a sus gobernadores y demás funcionarios sin intervención del gobierno federal.

La enmienda establece un nuevo artículo $105^{\circ}$, “...La duración de los mandatos de los miembros de los poderes Legislativo y Ejecutivo será igual a la de los cargos nacionales correlativos y su elección simultánea con la de éstos...”, determina la igualdad de periodos en todos los ámbitos, así como su elección, evitando, como si fuera algo malo, las elecciones de medio término.

El artículo $3^{\circ}$ del Estatuto Fundamental, dejaba fuera de aplicación varios artículos de la Constitución Nacional de 1853 con las reformas de 1860, 1866, 1898 y 1957, entre ellos la última parte del inciso $18^{\circ}$ del Artículo $67^{\circ}$ que decía "hacer el escrutinio y rectificación de ella", así como tampoco se aplicarían los 
artículos $82^{\circ}$-escrutinio de elección de presidente por la Asamblea Legislativa-, $83^{\circ}, 84^{\circ}$ y $85^{\circ}$ de la Constitución Nacional, sobre el procedimiento del escrutinio y votación de la fórmulas presidenciales del Colegio Electoral, como consecuencia que la elección se convierte en directa.

Tengamos presente que el Colegio Electoral pensado por los constituyentes de 1853, había establecido la igualdad de las Provincias entre sí, debido que el candidato a presidente debería conseguir un número de electores suficientes -mitad más uno- para lograr su consagración como presidente, el sistema de elección indirecta, evitaba que la o las provincias de mayor cantidad de habitantes definieran una elección presidencial, siendo así en igual peso político la Provincia de Jujuy que la de Buenos Aires, pero existiendo una diferencia inigualable si se equiparaba en cantidad de habitantes entre ambas.

Por último, el Estatuto Fundamental, en su artículo $4^{\circ}$, establecía la vigencia de la enmienda, rigiendo hasta el 24 de mayo de 1977. Si una Convención Constituyente no decidiere acerca de la incorporación definitiva al texto constitucional, o su derogación total o parcial, antes del 25 de agosto de 1976, su vigencia quedará prorrogada hasta el 24 de mayo de 1981, fecha definitiva en que debía ser aceptada por una Convención Constituyente, en dicha fecha la República Argentina se encontraba bajo otro gobierno cívico militar, por lo cual la enmienda perdería vigencia y se restablecería la Constitución de 1853 con las reformas de 1860. 1866, 1898 y 1957, una vez retornada la democracia el 10 de diciembre de 1983.

\section{Conclusiones}

¿Cuál es la importancia de esta enmienda?, justamente que fue aplicada, en la elecciones para autoridades del 11 de marzo de 1973 , que fueron convocadas por ley $19895^{18}$, en la que

18 Publicada en el Boletín Oficial el 26 de octubre de 1972. 
resultara electo Héctor Cámpora ${ }^{19}$ como nuevo presidente y se aplicara en la elección del 23 de septiembre de 1973 en la que fue elegido por tercera vez Juan Domingo Perón ${ }^{20}$, ambos fueron electos por periodos de cuatro años según la enmienda, es decir que sus mandatos culminaban en 1977.

En 1977, se debía producir una nueva elección presidencial por periodo de cuatro años, abarcando el lapso de 1977 a 1981, hecho no ocurrido por el golpe cívico militar del 24 de marzo de 1976, el gobierno de María Estela Martínez de Perón ${ }^{21}$, había anunciado el adelanto de las elecciones para octubre de 1976, el golpe cívico militar evito las mismas, lo cual demostró una vez más que no era el periodo constitucional en su duración el problema en sí, sino los intereses de distintos sectores, siendo el castrense que funcionaba como el "Partido Militar", otro factor de poder que participaba de manera ilegal en las decisión políticas, asimismo esa participación militar, no dejaban funcionar la democracia, solo el consenso, las políticas de estado en diversos temas, los acuerdos entre fuerzas democráticas, posibilitan el funcionamiento de las democracias.

La enmienda de 1972, fue una mala experiencia, pensada desde un "laboratorio" donde se suponía que saldría la mejor versión de una constitución, el tiempo demostraría que estaba alejada del sustento y la legitimidad que solo el pueblo votando puede otorgar.

La reforma constitucional de 1994, con sus aciertos y errores, seguramente hoy a la distancia con muchas modificaciones que se podrían llevar adelante, ha mantenido su vigencia gracias a los acuerdos de carácter democrático que la llevaron adelante.

\footnotetext{
19 1909-1980, odontólogo y político argentino, presidente de la Nación Argentina entre mayo y julio de 1973.

20 1895-1974, político, militar y escritor argentino, presidente de la Nación Argentina entre 1946 a 1952; 1952 a 1955 y 1973 a 1974.
}

21 1931, presidenta de la Nación entre 1974 a 1976. 